\title{
Prescripción extintiva de la acción y legislación local Por Carlos Botassi
}

\section{I - Introducción. Centralistas y Autonomistas}

Desde la década del '30 del siglo anterior se polemizó respecto de la potestad provincial para establecer plazos de prescripción en materia tributaria, tanto para la acción de cobro que titulariza el Fisco como para la demanda de repetición que puede ensayar el contribuyente.

Aunque a primera vista parezca una cuestión exclusivamente relacionada con la extinción de un tipo especial de obligaciones por el transcurso del tiempo, si bien se mira el tema reviste trascendencia institucional desde dos vertientes, ambas de nivel constitucional. En primer término clarificar y definir las atribuciones de la Nación y de las provincias en un asunto que tiene que ver con los recursos de estas últimas y, por añadidura, con su efectiva autonomía. En segundo lugar porque impone trazar una línea divisoria -lo más clara posible- entre el Derecho Privado cuya regulación compete al Estado Federal y el Derecho Público reservado a los Estados locales.

Desde las primeras especulaciones doctrinarias y a partir del dictado de los primeros fallos se perfilaron dos posiciones antagónicas: la tesis centralista o iusprivatista que reivindica la materia para la Nación y la posición autonomista o iuspublicista que se pronuncia a favor de la competencia local. Las discusiones, que cabe presumir mantendrán su vigencia debido al reparo de tipo constitucional que provoca la toma de posición autonomista del Código Civil y Comercial de 2015, alcanzaron un notable nivel científico, llegándose a fundamentar las posiciones con agudas reflexiones sobre los caracteres del federalismo argentino (el formal y el real); el papel de las provincias en su lucha por hacer realidad los objetivos proclamados en el Preámbulo de la Carta Magna; el régimen republicano; los antecedentes históricos y el pensamiento de los padres fundadores; la influencia de las teorías unitarias; la cohesión de la unidad nacional; el alcance del llamado "derecho común" y la autonomía del Derecho Tributario y del Derecho Administrativo.

Debe tenerse en cuenta que se suman a la cuestión sustancial del plazo de prescripción aspectos accesorios pero trascendentes como la manera de considerar su curso ${ }^{1}$; las causales de suspensión e interrupción; el momento procesal adecuado para oponer la prescripción y otras cuestiones de detalle que pueden presentarse en el contorno infinito del proceso.

\footnotetext{
${ }^{1}$ Así por ejemplo, luego de mantener vigente durante largo tiempo el plazo decenal, la Provincia de Buenos Aires estableció un plazo de prescripción de 5 años, en apariencia idéntico al previsto en el artículo 4027 inc. $3^{\circ}$ del Código Civil. Sin embargo, el legislador bonaerense, con evidente ánimo recaudatorio, dispuso que el curso del plazo extintivo de la acción comenzara a correr en períodos fiscales subsiguientes al de la fecha de vencimiento del impuesto. De esta manera solapada se alongó el plazo y la coincidencia con la regla de derecho común, que aventaría el riesgo de tacha constitucional, fue solo aparente.
} 
Para adentrarnos en el asunto comenzaremos por recordar que los centralistas o iusprivatistas estiman que definir los medios de extinción de las obligaciones, entre los que se cuenta la prescripción, no forma parte de la potestad tributaria local sino que conforma materia propia del Código Civil, cuyo dictado es atribución exclusiva de la Nación (constitución Nacional, art. 75 inc. 12). En definitiva -afirman- ha sido decisión del constituyente que en todo el territorio argentino exista una única regulación del derecho de las obligaciones.

En cambio, los autonomistas o iuspublicistas -entre los que nos enrolamos- consideran que los poderes tributarios de las provincias, municipios y Ciudad Autónoma de Buenos Aires, deben considerarse reservados excepto delegación expresa a la Nación que -naturalmente- también goza del poder de imposición federal. Se trata de una atribución inherente a la autonomía e imprescindible para la supervivencia de los Estados locales (arts. 1, 4, 5, 75 incs. $1^{\circ}$ y 2o $, 121,123,126$ y 129 de la Constitución Nacional). Si se reconoce a las provincias y a la C.A.B.A. el poder de establecer impuestos, tasas y contribuciones, determinando su forma de pago, con posibilidades de fiscalizar y penalizar el incumplimiento del contribuyente (esto es atender todo lo pertinente a la denominada potestad tributaria "aplicativa"), deviene natural que sean los mismos poderes locales quienes determinen el plazo de vigencia de la acción judicial de cobro. Al mismo tiempo, con un enfoque extensivo que correlaciona con señeros principios generales ("quien puede lo más puede lo menos" y "lo accesorio debe seguir la suerte de lo principal”), también corresponde reconocer a las autoridades locales la atribución de fijar el momento de arranque del cómputo de dicho plazo, las causales de suspensión e interrupción y otras cuestiones accesorias. En definitiva, tratándose de asuntos de Derecho Público (Tributario y Administrativo), de reconocido carácter local ante la ausencia de delegación constitucional al Poder Central, la cuestión del plazo prescriptivo y sus circunstancias no deben considerarse parte de los códigos de derecho común cuyo dictado compete a la Nación.

\section{II - Doctrina de la Corte Suprema de Justicia de la Nación y su réplica}

Con referencia a las atribuciones recaudatorias locales, y como no podía ser de otra manera, la Corte Nacional señaló que "de acuerdo con la distribución de competencias que emerge de la Constitución Nacional los poderes de las provincias son originarios e indefinidos (art. 121), en tanto que los delegados a la Nación son definidos y expresos (art. 75), razón por la cual no es objetable la facultad de las provincias para darse leyes y ordenanzas de impuestos y, en general, todas las que juzguen conducentes a su bienestar y prosperidad, sin más limitaciones que las enumeradas en el art. 108 (actual 126) de la Constitución”"2. Empero, en cuanto respecta a la cuestión del plazo de prescripción,

\footnotetext{
${ }^{2}$ CSJN, "Entre Ríos, Provincia de c/ Estado Nacional s/ acción declarativa de inconstitucionalidad", 10.6.2008, Fallos 331:1412.
} 
el criterio imperante en la jurisprudencia de la Corte Suprema de Justicia de la Nación, desde las primeras décadas del siglo pasado, ha sido el centralista o iusprivatista ${ }^{3}$.

En materia de repetición de impuestos el Tribunal aplicó las disposiciones del código Civil declarando la inconstitucionalidad de las normas locales que se apartaban de su régimen ${ }^{4}$.

Esta doctrina primigenia se cual mantuvo y enfatizó al sentenciar la Corte la célebre causa Filcrosa, estatuyendo una vez más que en materia de prescripción toda norma provincial o municipal que se aparte de la legislación de fondo resulta inválida, ya que no se trata solo de regular un medio de extinción de las obligaciones sino que se involucran cuestiones vinculadas con el derecho de propiedad, es decir con el derecho común contenido en los códigos de fondo. Destacó entonces el Alto Tribunal que "la regulación de los aspectos sustanciales de las relaciones entre acreedores y deudores corresponde a la legislación nacional, por lo que no cabe a las provincias -ni a los municipios- dictar leyes incompatibles con lo que los códigos de fondo establecen al respecto ... y ello pues, aun cuando los poderes de las provincias son originarios e indefinidos y los delegados a la Nación son definidos y expresos, es claro que la facultad del Congreso Nacional de dictar los códigos de fondo, comprende la de establecer las formalidades que sean necesarias para concretar los derechos que reglamenta y, entre ellas, la de legislar de manera uniforme sobre los aludidos modos de extinción de las obligaciones", de tal suerte que "todas las obligaciones deben ajustarse al régimen general de prescripción establecido en los Códigos de fondo", que configura "un instituto común al Derecho Público y al Privado, lo que descarta el riesgo de que, por la vía de aplicar aquella norma, la cuestión sea juzgada a la luz de pautas indebidamente trasladadas a un ámbito que le es impropio ... La prescripción no es un instituto propio del Derecho Público local, sino un instituto general del derecho, lo que ha justificado que, en ejercicio de la habilitación conferida al legislador nacional por el citado art. 75 inc.12, éste no sólo fijara los plazos correspondientes a las diversas hipótesis en particular, sino que, dentro de ese marco, estableciera

${ }^{3}$ CSJN, "Banco de la Nación Argentina c/ Prov. Buenos Aires", 20.7.1936, Fallos 175:300; María Diehl c/ Prov. de Buenos Aires”, 20.10.1936, Fallos 176:115. Estos antecedentes hicieron que el Superior Tribunal afirmara que "desde antiguo esta Corte ha resuelto que tratándose de una demanda que tiende a obtener la repetición de sumas pagadas a una Provincia en concepto de impuestos, que se sostiene son inconstitucionales, el plazo de prescripción aplicable es el establecido por el art. 4023 del Código Civil (Fallos 180:96) y que una ley local no puede derogar las leyes sustantivas dictadas por el Congreso porque ello importa un avance sobre facultades exclusivas de la nación, contrario al art. 67 inc. $11^{\circ}$ (hoy art. 75 inc. $12^{\circ}$ ) de la Ley Suprema" (Causa S.A. de Exportación de Cereales Nidera Argentina c/ Provincia de Entre Ríos”, 1.12.1972, Fallos 284:458).

${ }^{4}$ V. gr. CSJN, Francisco Archia c/ Prov. de Buenos Aires, 2.7.1904, Fallos 100:5; Juan Ghiggeri c/ Prov. de Buenos Aires, 17.4.1906, Fallos 104:143; Fisco de la Prov. de Entre Ríos c/ Simón Tegbi, 2.8.1943, Fallos 196:274. 
también un régimen destinado a comprender la generalidad de las acciones susceptibles de extinguirse por esta vía"s.

Partiendo de una regla constitucional de inspiración unitaria ${ }^{6}$, como lo es el artículo 75 inc. 12, la Corte arriba sin sobresaltos a argumentaciones axiológicas sustanciales, llegando a sostener que la interpretación centralista reflejaba "el propósito de los constituyentes de contribuir a la creación de aquellos lazos de unidad entre las provincias y sus integrantes necesarios para fundar la República, evitar los peligros insitos en la dispersión de soluciones concernientes a institutos generales que quedarían librados -pese a tal generalidad- al criterio particular de cada legislatura local"?.

En rigor, recordando que nuestro sistema de gobierno no es solo republicano sino también federal y que al inciso 12 del art. 75 se opone con igual fuerza el art. $121^{8}$, también podría sostenerse que merece aceptación la teoría opuesta, debido a que afianza el federalismo, evita la intromisión de la Autoridad Central en cuestiones de Derecho Público local y garantiza el funcionamiento autónomo de una función provincial esencial: hacer eficiente su recaudación de la cual depende su supervivencia.

\section{III - La opinión premonitoria de la ministra Argibay}

La doctrina cimera de Filcrosa fue reiterada por la Corte al fallar Casa Casmma9. En este caso reviste especial interés el obiter dictum de la Dra. Cármen Argibay, quien mostró su decepción ante la ausencia de una actividad legislativa que saliera al cruce de la jurisprudencia de la Corte que, claramente, avanzaba sobre la autonomía provincial. Señaló entonces que el criterio imperante en el Alto Tribunal "no ha merecido respuesta alguna del Congreso Nacional, en el que están representados los Estados provinciales y cuenta con la posibilidad de introducir precisiones en los textos legislativos para derribar así las

\footnotetext{
${ }^{5}$ CSJN, Recurso de hecho deducido por Abel Latendorf (síndico) en la causa Filcrosa S.A. s/ quiebra s/ incidente de la Municipalidad de Avellaneda, 30.9.2003, Fallos: 326:3899.

6 "Las materias que integran la cláusula de los códigos o derecho común y las normas federales son tan amplias que concentran en el Poder Legislativo una sustantiva cuota de poder unitario" (Gelli 2008).

${ }^{7}$ CSJN, Recurso de hecho deducido por Abel Latendorf (síndico) en la causa Filcrosa S.A, citado.

${ }^{8}$ Para Varela el sentimiento federal está tan arraigado en nuestra nacionalidad que hunde sus raíces en un hecho de enorme trascendencia política e institucional: la incorporación en 1810 a la Junta Provisional Gubernativa, instalada en Buenos Aires, de los diputados enviados por las provincias. Así el nuevo gobierno asume un cambio de planes radical: "del unitarismo de la Primera Junta, organizada por el Municipio de Buenos Aires, se pasaba al federalismo de un Ejecutivo organizado por todos los municipios de las Provincias" (Varela, Luis V., Historia Constitucional de la República Argentina, Taller de Impresiones Oficiales, La Plata, 1910, t. I p. 354).

${ }^{9} \mathrm{CSJN}$, Recurso de hecho deducido por Casa Casmma SRL s/ concurso preventivo s/ incidente de la Municipalidad de La Matanza, 26.3.2009, Fallos 332:616.
} 
interpretaciones judiciales de las leyes, si de alguna manera se hubiera otorgado a éstas un significado erróneo"10.

Aunque al emitir su voto en Casa Casmma (2009) todavía faltaban tres años para la elevación del Proyecto Lorenzetti al Poder Ejecutivo (2012), el cual nada dispuso respecto al tema ${ }^{11}$, lo cierto es que el reclamo de intervención legislativa efectuado por la Dra. Argibay pareció ser escuchado al redactarse y sancionarse el texto definitivo del artículo 2532 del CCyC en el cual se agregó un trascendente segundo párrafo al texto de la Comisión:

"Ámbito de aplicación. En ausencia de disposiciones específicas, las normas de este Capítulo son aplicables a la prescripción adquisitiva y liberatoria. Las legislaciones locales podrán regular esta última en cuanto al plazo de tributos".

De esta forma el art. 2532 consagra una regla general y su inmediata excepción en materia de prescripción extintiva en materia de tributos.

\section{IV - Los criterios jurisprudenciales locales}

En 1983 la polémica se había reavivado como consecuencia del fallo plenario dictado por la Cámara Nacional de Apelaciones en lo Civil ${ }^{12}$, estableciendo que el plazo decenal de prescripción en materia de tasas, hasta entonces aceptado en aplicación del art. 4023 del Código Civil, debía trocar hacia el plazo de cinco años contemplado en el art. 4027 inc. $3^{\circ}$.

Algunos años más tarde la Corte Nacional abrió una brecha en el camino al reconocimiento de las atribuciones locales en un caso vinculado a la prescripción de créditos de naturaleza previsional y, por tanto, de prevalente aplicación del Derecho Público local ${ }^{13}$. En la Provincia de Buenos Aires la cuestión fue abordada por la doctrina y la jurisprudencia con motivo de la proliferación de reglas jurídicas y "técnicas" destinadas a ampliar la recaudación fiscal ${ }^{14}$. La Suprema Corte de Justicia bonaerense, más allá de algunas decisiones opacas y de la opinión personal contraria de varios de sus miembros,

${ }^{10}$ La Dra. Argibay reiteró estas apreciaciones en varias sentencias posteriores.

${ }^{11} \mathrm{El}$ art. 2532 del Proyecto se limitó a establecer que "en ausencia de disposición específica, las normas de este Capitulo son aplicables a la prescripción adquisitiva y liberatoria”, consagrando la regla general conservada como primer párrafo del art. 2532 del CCyC de 2015.

${ }^{12}$ Cám. Nac. Civ. en pleno, Obras Sanitarias de la Nación c/ Galvalisi, José y otros, 30.3.1983, La Ley 1983-B-615. La votación reflejó las dos posturas opuestas, desgranándose sesudos argumentos tanto a favor de la postura centralista como de la autonomista. La tesis iusprivatista se impuso por mayoría.

${ }^{13}$ CSJN, Santos, Ramiro c/ I.S.S. de Tucumán, 15.8.1989, Fallos 312:1340.

14 "La incesante creatividad de los Fiscos locales tendientes a introducir continuas modificaciones y regulaciones para preservar el crédito fiscal en una medida similar a la responsabilidad de los funcionarios que no han perseguido adecuadamente su percepción" (Colli, Hernán Ariel, Prescripción en el Código Fiscal de la Provincia de Buenos Aires, en Proceso Tributario Bonaerense, Botassi, Carlos A. y Oroz, Miguel H. E. (Directores), Mammoni, Gustavo A. (Coordinador), Librería Editora Platense, La Plata, 2a edición, 2014, p. 656. 
invocando razones de economía procesal, siguió el sendero marcado por la Corte Federal y consideró prudente acatar la doctrina de Filcros $a^{15}$.

En la Ciudad Autónoma de Buenos Aires la jurisprudencia se mostró errática. En el caso Marini el Superior Tribunal de Justicia hizo suyo el criterio iusprivatista de la Corte Nacional $^{16}$, mientras al sentenciar Sociedad Italiana de Beneficencia ${ }^{17}$, reivindicó la potestad local, recordando que los fallos de la Corte Suprema de Justicia de la Nación solo obligan en el caso concreto y que la regulación de la materia tributaria -consecuencia de la autonomía- incluye lo atinente al plazo de la prescripción de las acciones de cobro o repetición de impuestos. Sancionado y publicado el Código unificado (Ley 26.994, B.O. 8.10.2014), pero antes de su entrada en vigencia que se produciría el $1^{\circ}$ de agosto de 2015, la Sala III de la Cámara Contencioso Administrativa celebró el triunfo de la tesis autonomista reflejado en la parte final de su artículo 2532: "Si bien el Código Civil y Comercial de la Nación no se encuentra aun vigente, lo cierto es que forma parte del derecho argentino, ya que ha sido sancionado y promulgado y por ende no puede ser ignorada la inequívoca voluntad del Congreso Nacional de no legislar en materia de prescripción de tributos locales y de que esa facultad sea ejercida por las legislaturas locales"18.

\section{V - Los artículos 2532 y 2560 del código unificado. Su constitucionalidad}

El Código Civil y Comercial dedica su Libro Sexto (y último) a reglar Disposiciones comunes a los derechos personales y reales. Su Título I aborda la Prescripción y caducidad, dedicando su Capítulo 1 a las Disposiciones comunes a la prescripción liberatoria y ad-

\footnotetext{
${ }^{15}$ SCJBA, Fisco de la Provincia de Buenos Aires s/ incidente de revisión en autos Coop. Provisión Almaceneros Minoristas de Punta Alta s/ concurso preventivo, 30.5.2007. En el caso se declaró la inconstitucionalidad del art. 119 del Código Fiscal que establecía un sistema escalonado para la reducción a 5 años del plazo de prescripción de 10 años hasta entonces vigente. La mayoría del Tribunal dejó a salvo su opinión contraria a la doctrina centralista de la Corte Nacional pero consideró que debía ser seguida "por razones de economía procesal". Los Dres. de Lazzari y Pettigiani, en cambio optaron por desarrollar sus propias posturas, y al votar en disidencia, explicaron que la materia tributaria y sus particularidades (entre las que se encuentra el plazo de prescripción) no había sido delegada a la Nación, formando parte del Derecho Administrativo (local por definición) que no puede ser desplazado por normas generales destinadas a regular relaciones de carácter privado.

${ }^{16}$ Tsjcaba, Marini, Osvaldo Oscar s/queja por recurso de inconstitucionalidad denegado en: GCBA c/Osvaldo Marini s/ej. fisc. - avalúo (expte. N 9070/12).

${ }^{17}$ TSJCABA, Sociedad Italiana de Beneficencia c/ Dción. General de Catastro, 17.11.2003, La Ley 2004-D-270.

${ }^{18}$ Cám. Contenciosoadm. y Trib. CABA, Sala III, Gobierno de la Ciudad de Buenos Aires c/ A.G.M. Argentina S.A.", 9.3.2015, La Ley 2015-C-328, con nota crítica de Menna, Juan O. y Brandt, Germán, Aplicación anticipada del Código Civil y Comercial. Prescripción en materia de tributos locales.
} 
quisitiva ${ }^{19}$. Al fundamentar el Proyecto, la Comisión redactora explicó que mantuvo "la metodología del Código Civil vigente, estableciendo un plazo de prescripción genérico y regulando casos específicos. En todos los casos se ha procurado la actualización de los plazos regulados, intentando la unificación y la reducción en cuanto resulta conveniente y ajustado al valor seguridad jurídica y a la realidad actual".

Debido a la modificación por el Senado de los artículos 2532 y 2560 del Proyecto ya no existe la invocada "unificación y reducción de plazos" (al menos en materia de tributos locales $)^{20}$.

La Sección 1ª, Normas Generales, se inicia con el artículo 2532:

Ámbito de aplicación: En ausencia de disposiciones específicas, las normas de este Capítulo son aplicables a la prescripción adquisitiva y liberatoria. Las legislaciones locales podrán regular esta última en cuanto al plazo de los tributos.

A su turno, el artículo 2560, ubicado en el Capítulo 2, Prescripción liberatoria, Sección 2a, Plazos de prescripción, dispone:

Plazo genérico. El plazo de la prescripción es cinco años, excepto que esté previsto uno diferente en la legislación local.

Los textos transcriptos, que reconocen la potestad local para establecer plazos diferentes a los fijados por el legislador nacional, no pertenecen a la Comisión Redactora. Su introducción en la redacción final del Poder Ejecutivo proporciona noticia de que se partió de un criterio centralista para después, como quien se desprende voluntariamente de potestades propias, "delegar" en las autoridades locales la posibilidad de introducir variantes en el acotado ámbito del Derecho Público.

Del juego armónico de ambos artículos cabe inferir que la referencia en exclusividad a la materia tributaria del art. 2532 resulta ensanchada por el art. 2560 que no contiene limitación alguna; aunque -como es obvio- las provincias y la Ciudad Autónoma de Buenos Aires no podrán establecer otros plazos de prescripción como no sean los relacionados con obligaciones propias del Derecho Público (Administrativo, Tributario, Previsional, Disciplinario, Sancionatorio). En otras palabras: la generalidad del art. 2560 permite a los poderes locales sumar a la regulación en materia tributaria, otros plazos relacionados con créditos fiscales regidos por el Derecho Público: obligaciones previsionales;

\footnotetext{
${ }^{19}$ Respecto del tratamiento general del tema en el Código unificado remitimos a Calvo Costa, Carlos A., Prescripción extintiva o liberatoria en el Código Civil y Comercial de la Nación, Suplemento Especial Nuevo Código Civil y Comercial, La Ley, Buenos Aires, 2014, p. 237; Márquez, Fernando y Calderón, Maximiliano R., Prescripción y caducidad en el Código Civil y Comercial, La Ley, 2015-C-743.

${ }^{20}$ Por su parte, recibido el texto de la Comisión Redactora y antes de remitirlo al Parlamento, el Poder Ejecutivo introdujo modificaciones a los artículos 14, 240, 241, 765, 766, 804, 1243 , $1685,1764,1765,1766$ y 2635 . Reviste especial interés el giro de 180 grados producido al eliminarse la regulación de la responsabilidad del Estado y de los funcionarios públicos que aparecía en los artículos 1764, 1765 y 1766 del Proyecto, materia que quedó remitida a las normas de Derecho Administrativo nacional o local según corresponda.
} 
sanciones pecuniarias; cargos a agentes estatales por mal manejo de fondos públicos; débitos por insuficiente rendiciones de cuentas y de viáticos u otros tipos de anticipos dinerarios; etc.

Pero, además, por tratarse de materia ajena al Derecho Privado, quedan sometidas a la regulación local aquellos créditos titularizados por particulares contra el Estado: obligaciones derivadas de sentencias firmes por responsabilidad estatal; deudas a proveedores y contratistas; sueldos y accesorios de agentes públicos; etc. En estas materias las provincias y la C.A.B.A. - mediante ley formal ya que se trata de reglar derechos patrimoniales que gozan de amparo constitucional- pueden establecer plazos superiores o inferiores a los cinco años establecidos en el art. 2560 que funciona como norma de aplicación subsidiaria.

La técnica legislativa empleada registra alguna imperfección. Por lo pronto, frente al art. 2560 que consagra la regla general del carácter local de la prescripción en toda materia de Derecho Público, cabe preguntarse ¿cuál fue el sentido de particularizar el asunto respecto de los tributos en el art. 2352? Una respuesta posible pasa por advertir que en el Proyecto de la Comisión Lorenzetti no existía el remate de la parte final del art. 2560 ("excepto que esté previsto uno diferente en la legislación local") introducida por el Poder Ejecutivo. Tampoco se había proyectado la excepción puntual de la materia tributaria incorporada por el Poder Ejecutivo en la parte final del art. $2532^{21}$.

Se trata, en cualquier caso, de una política legislativa absolutamente opuesta a la adoptada en otras cuestiones de Derecho Administrativo reguladas en el nuevo Código. El ejemplo paradigmático es la responsabilidad del Estado, ámbito donde las disposiciones del CCyC "no son aplicables de manera directa ni subsidiaria" (art. 1764 en correlato con el art. $1^{\circ}$ de la Ley 26.944), más allá de la eventual aplicación analógica de las normas del CCyC.

Finalmente cabe señalar que los plazos de prescripción que establezcan las provincias y la C.A.B.A. deberán resultar razonables (art. 28 de la Constitución Nacional). El lapso

\footnotetext{
${ }^{21}$ Proyecto, art. 2560: "Plazo genérico. El plazo de la prescripción es de cinco años, excepto que este previsto uno diferente". Art. 2532: "Ámbito de aplicación. En ausencia de disposición específica, las normas de este Capítulo son aplicables a la prescripción adquisitiva y liberatoria”. Código Civil y Comercial, art. 2560: "Plazo genérico. El plazo de la prescripción es de cinco años, excepto que este previsto uno diferente en la legislación local". Art. 2532: "Ámbito de aplicación. En ausencia de disposición específica, las normas de este Capítulo son aplicables a la prescripción adquisitiva y liberatoria. Las legislaciones locales podrán regular esta última en cuanto al plazo de tributos".

Como es lógico en el criterio de la Comisión Redactora se preveían las excepciones al plazo genérico dentro del mismo régimen del CCyC (v. gr. plazo de 3 años para la acción indemnizatoria; plazo de 2 años para la acción de nulidad) ya que no se reconocía ingerencia alguna a los sistemas locales. En cambio, la normativa finalmente sancionada otorga protagonismo a las provincias y la C.A.B.A. legitimando el establecimiento de sus propios plazos de prescripción siempre que se trate de obligaciones regidas por el Derecho Público.
} 
de cinco años establecido en el Código Civil y Comercial, sin ser obligatorio para el legislador local, debe marcar la tendencia.

En cuanto a la validez constitucional del nuevo régimen, las opiniones doctrinarias aparecen divididas. Para Spisso, que comparte las argumentaciones volcadas por la Corte en Filcrosa, la remisión a los poderes locales resulta inconstitucional por contradecir lo prevenido en el art. 75 inc. 12, mostrándose partidario de los textos proyectados por la Comisión que, como antes vimos, nada decían respecto de la atribución provincial para fijar el plazo de prescripción en materia tributaria ${ }^{22}$.

Otros autores, enrolados en la tesis iuspublicista, han encontrado plausible el enfoque autonomista del Congreso que se tradujo en las agregadas frases finales de los artículos 2532 y 2560 , señalando que "en rigor, lo que básicamente ha existido es una divergencia en cuanto al sentido y el alcance de la delegación de facultades efectuada en el art. 75 inc. 12 y ratificada en el art. 126 de la Constitución Nacional", que se limita a los códigos allí indicados (Civil, Comercial, Penal, Minería, Trabajo y Seguridad Social), sin incluir "la facultad para dictar una legislación unificada respecto de aquellas materias que no son propios de esos códigos, como son las que integran los contenidos del Derecho Administrativo y Tributario local, aunque se refieran a los aspectos sustanciales de las relaciones entre acreedor y deudor"23.

Junto a las opiniones de los autores existe algún antecedente jurisprudencial. El Superior Tribunal de Justicia de la Ciudad Autónoma de Buenos Aires, ratificando su postura "rebelde" respecto del criterio centralista de la Corte Nacional, en sentencia dictado dos meses después de la entrada en vigencia del Código unificado, recordando las reflexiones de la Ministro Argibay en Casa Casmma, se congratuló de la "novedosa concepción plasmada en el Código de fondo respecto de las facultades de las autonomías locales para legislar el instituto de la prescripción en materia tributaria ... De acuerdo a cómo el Congreso ha legislado -interpretando el alcance y sentido de nuestra Constitución- ha quedado evidenciado que, contrariamente a la tesis iusprivatista seguida por la Corte, concierne al ámbito del derecho público local legislar el régimen de la prescripción en materia tributaria, sin contrariar ello el art. 75 de la $\mathrm{CN}^{\prime 24}$.

22 Spisso, Rodolfo R., Prescripción liberatoria de tributos provinciales en el Código Civil y Comercial, La Ley 2014-F-1239, quien afirma: "Por lo demás, de acuerdo a tales desafortunadas innovaciones tendríamos distintos plazos de prescripción liberatoria, el que fijen las provincias y sus municipalidades en materia tributaria y el que fije el Código Civil y Comercial para las demás materias reguladas por la legislación local”.

${ }^{23}$ Padulo, Adriana María A., El Código Civil y Comercial y la Facultad de las Provincias y de la Ciudad Autónoma para regular la prescripción en el Derecho Tributario, La Ley 2015-A-643, especialmente pp. 645 y sigs. Asimismo han celebrado las disposiciones de CCyC: Abalos, María Gabriela, ¿El fin de la doctrina Filcrosa? A propósito de la sanción del nuevo Código Civil y Comercial de la Nación, La Ley 2015-B-804, especialmente p. 812;

${ }^{24}$ STJCABA, Expte. 11148/14, Fornaguera Sempe y otros c/ Gobierno de la Ciudad de Buenos Aires s/Demanda contra la Autoridad administrativa s/ recurso de inconstitucionalidad con- 


\section{VI - Interrupción y suspensión del curso de la prescripción}

La remisión a la "legislación local" del art. 2560 plantea una duda respecto de su alcance: ¿debe estimarse limitado al plazo o puede considerarse extendido a otras cuestiones propias de la prescripción, como las causales de interrupción y suspensión de su curso? Cabe recordar que, al sentenciar Casa Casmma, seis años antes de la entrada en vigencia del Código unificado, la Corte Suprema de Justicia de la Nación, de manera coherente con su postura centralista, había considerado improcedente que las autoridades locales reconocieran efecto interruptivo al reclamo administrativo previo a la demanda judicial o establecieran causales de suspensión y/o interrupción del curso de la prescripción ${ }^{25}$. Empero ahora ha cambiado la normativa y los artículos 2532 y 2560 del nuevo Código dieron condición de derecho positivo al principio autonomista. Se impone entonces revisar aquella doctrina. Existen, como siempre ocurre en Derecho, argumentos atendibles para las dos posibles respuestas al interrogante recién formulado.

A favor de la potestad local de regular las cuestiones accesoria se sostiene que, si bien las nuevas reglas aluden exclusivamente al plazo, no es menos cierto que la suspensión y la interrupción configuran asuntos accesorios al curso del término extintivo de la acción y bien podría echarse mano del apotegma "quien puede lo más puede lo menos". Reconocer a las autoridades locales la potestad para establecer la duración con vida del crédito lleva implícito regular las contingencias que podrían afectar el plazo de prescripción. En la vereda opuesta se señala que las provincias han delegado a la Nación el dictado del Código Civil que incluye, claro está, todo lo atinente a las obligaciones y sus medios de extinción, la excepción de los artículos 2532 y 2560 -como tal- debe interpretarse restrictivamente, en su concreta literalidad y acotarse a la cuestión del plazo, sin que extensivamente puedan sumarse asuntos tales como la manera de contar su cómputo y las causales de suspensión e interrupción.

La disputa no es novedosa ya que al tiempo que establecieron sus propios plazos de prescripción en materia tributaria, las provincias estatuyeron las causales de interrupción y suspensión de su curso ${ }^{26}$. Así por ejemplo en materia de interrupción, la Provincia de

cedido, sent. del 23.10.2015, donde también se dijo: "En tales condiciones, el Código Civil y Comercial de la Nación sancionado por el órgano competente para fijar el alcance y contenido del derecho común ha venido a validar la tesis que este Tribunal sentara en sus decisiones referida a la autonomía local para reglar el plazo de prescripción de los tributos de la jurisdicción -independientemente de la fecha de entrada en vigencia del nuevo plexo, y de los aspectos de derecho intertemporal-; y existen suficientes razones para apartarse de la jurisprudencia anterior sentada por la CSJN sobre esta materia".

${ }^{25} \mathrm{CSJN}$, Casa Casmma SRL s/ concurso preventivo. Incidente de verificación tardía Municipalidad de la Matanza, 26.3.2009.

${ }^{26}$ Con relación a la Provincia de Buenos Aires puede verse el detallado estudio efectuado por Colli, Hernán Ariel, Prescripción en el Código Fiscal de la Provincia de Buenos Aires, en Botassi, Carlos A. y Oroz, Miguel H. E. (Directores), Mammoni, Gustavo A. (Coordinador), Procedimiento tributario bonaerense, Platense, La Plata, $2^{\text {a }}$ edición, 2014, pp. 718 y sigs. 
Buenos Aires ha enunciado un nutrido listado de hechos y circunstancias que aniquilan todo el tiempo transcurrido, reduciéndolo a cero para recomenzar en la forma indicada en cada caso (arts. 160 del Código Fiscal bonaerense, texto ordenado por Dec. $39 / 2011)^{27}$. El régimen se diferencia notoriamente del sistema del Código de Vélez ${ }^{28}$

${ }^{27}$ Art. 157 s/ Ley 14.333: "Prescriben por el transcurso de cinco (5) años las acciones y poderes de la Autoridad de Aplicación para determinar y exigir el pago de las obligaciones fiscales regidas por este Código y para aplicar y hacer efectivas las sanciones en él previstas. Prescribe por el transcurso de cinco (5) años la acción de repetición de gravámenes y sus accesorios... Los términos de prescripción quinquenal establecidos en el presente artículo, comenzarán a correr para las obligaciones fiscales que se devenguen a partir del $1^{\circ}$ de enero de 1996”. Art. 160 s/ Ley 14.333: "La prescripción de las acciones y poderes de la Autoridad de Aplicación para determinar las obligaciones fiscales y exigir el pago de las mismas se interrumpirá:

1) Por el reconocimiento expreso o tácito de la obligación impositiva por parte del contribuyente o responsable;

2) Por renuncia al término corrido de la prescripción en curso;

3) Por el inicio del juicio de apremio contra el contribuyente o responsable en los únicos casos de tratarse de impuestos determinados en una sentencia del Tribunal Fiscal de Apelación debidamente notificada, o en una intimación o resolución administrativa debidamente notificada y no recurrida por el contribuyente o, en casos de otra índole, por cualquier acto judicial tendiente a obtener el cobro de lo adeudado.

En los casos previstos en los incisos 1) y 2) del presente artículo, el nuevo término de prescripción comenzará a correr a partir del $1^{\circ}$ de enero siguiente al año en que las circunstancias mencionadas ocurran.

La prescripción de la acción para aplicar y hacer efectivas las sanciones se interrumpirá:

a) Por la comisión de nuevas infracciones, en cuyo caso el nuevo término de la prescripción comenzará a correr el $1^{\circ}$ de enero siguiente al año en que tuvo lugar el hecho o la omisión punible.

b) Por el inicio del juicio de apremio o por cualquier acto judicial tendiente a obtener su cobro, de corresponder.

La prescripción de la acción de repetición del contribuyente o responsable, se interrumpirá por la deducción de la demanda respectiva, el nuevo término de la prescripción comenzará a correr a partir del $1^{\circ}$ de enero siguiente al año en que se cumplan los ciento ochenta (180) días de presentado el reclamo.

En todos los casos, cuando se trate de obligaciones provenientes del Impuesto sobre los Ingresos Brutos, la interrupción del curso de la prescripción de las acciones y poderes de la Autoridad de Aplicación para determinar y exigir el pago del gravamen se extenderá a todo el ejercicio anual del tributo involucrado."

${ }^{28}$ Cód. Civil, art. 3986: "La prescripción se interrumpe por demanda contra el poseedor o deudor, aunque sea interpuesta ante juez incompetente o fuere defectuosa y aunque el demandante no haya tenido capacidad legal para presentarse en juicio". Art. 3989: "La prescripción 
y del Código unificado de $2015^{29}$.

Igual temperamento ha seguido la normativa provincial en materia de suspensión de la prescripción, a través del artículo 161 del Código Fiscal ${ }^{30}$ que se aparta en forma notable

es interrumpida por el reconocimiento expreso o tácito que el deudor o el poseedor hace del derecho de aquel contra quien prescribía".

${ }^{29} \mathrm{CCyC}$, art. 2545: "Interrupción por reconocimiento. El curso de la prescripción se interrumpe por el reconocimiento que el deudor poseedor efectúa del derecho de aquel contra quien prescribe". Art. 2546: "Interrupción por petición judicial. El curso de la prescripción se interrumpe por toda petición del titular del derecho ante autoridad judicial que traduce la intención de no abandonarlo, contra el poseedor, su representante en la posesión, o el deudor, aunque sea defectuosa, realizada por persona incapaz, ante tribunal incompetente, o en el plazo de gracia previsto en el ordenamiento procesal aplicable". Art. 2548: "Interrupción por solicitud de arbitraje. El curso de la prescripción se interrumpe por la solicitud de arbitraje. Los efectos de esta causal se rigen por lo dispuesto para la interrupción de la prescripción por petición judicial, en cuanto sea aplicable”. Art. 2550: “(Dispensa de la prescripción). Requisitos: "El juez puede dispensar de la prescripción ya cumplida al titular de la acción, si dificultades de hecho o maniobras dolosas le obstaculizan temporalmente el ejercicio de la acción, y el titular hace valer sus derechos dentro de los seis meses siguientes a la cesación de los obstáculos. En el caso de personas incapaces sin representantes el plazo de seis meses se computa desde la cesación de la incapacidad o la aceptación del cargo por el representante. Esta disposición es aplicable a las sucesiones que permanezcan vacantes sin curador, si el que es designado hace valer los derechos dentro de los seis meses de haber aceptado el cargo".

${ }^{30}$ Art. 161 s/ Ley 14553: "Se suspenderá por un (1) año el curso de la prescripción de las acciones y poderes de la Autoridad de Aplicación en los supuestos que siguen: a) Desde la fecha de intimación administrativa de pago de tributos determinados, cierta o presuntivamente, con relación a la acciones y poderes fiscales para exigir el pago intimado. Cuando mediare recurso de apelación ante el Tribunal Fiscal de Apelación la suspensión, hasta el importe del tributo liquidado, se prolongará hasta los noventa (90) días posteriores a que la Autoridad de Aplicación reciba las actuaciones en el marco de las cuales el Tribunal Fiscal hubiere dictado sentencia declarando su incompetencia, determinando el tributo, aprobando la liquidación practicada en su consecuencia o, en su caso, rechazando el recurso presentado contra la determinación de oficio. Cuando se hubiere interpuesto recurso de reconsideración ante el Director Ejecutivo de la Agencia de Recaudación de la Provincia de Buenos Aires, la suspensión se prolongará hasta los noventa (90) días posteriores a la notificación de la resolución respectiva. b) Desde la fecha de la resolución sancionatoria. Si mediare recurso de reconsideración ante el Director Ejecutivo de la Agencia de Recaudación de la Provincia de Buenos Aires, el término de la suspensión perdurará hasta los noventa (90) días posteriores a que la resolución de dicho recurso haya quedado firme o consentida. Si mediare recurso de apelación ante el Tribunal Fiscal de Apelación, o recurso o acción judicial, el término de la suspensión perdurará hasta los noventa (90) días posteriores a que la Autoridad de Aplicación reciba las actuaciones en el marco de las cuales se hubiere dictado la sentencia firme que confirme total o parcialmente la sanción. 
tanto del Código Civil derogado ${ }^{31}$ como del $\mathrm{CCyC}^{32}$.

c) Desde la fecha de la interposición, por el contribuyente o responsable, del recurso previsto en el artículo 24 inciso b) del Convenio Multilateral. En este caso, la suspensión, hasta el importe del tributo reclamado, se prolongará hasta noventa (90) días después de haber adquirido firmeza la resolución dictada por la Comisión Arbitral o Plenaria, según corresponda, salvo que a ese momento aún se encontrara pendiente la resolución de alguno de los recursos previstos en el artículo 115 de este Código, en cuyo caso la suspensión se prolongará conforme a lo establecido en el inciso a) de este artículo.

En caso de producirse denuncia penal, la suspensión de la prescripción se extenderá desde la fecha en que ocurra dicha circunstancia hasta el día en que quede firme la sentencia judicial dictada en la causa penal respectiva.

Se suspenderá por ciento veinte (120) días el curso de la prescripción de las acciones y poderes del Fisco para determinar y exigir el pago de los impuestos regidos por el presente Código, y para aplicar y hacer efectivas las multas, desde la fecha de notificación de la resolución de inicio del procedimiento de determinación de oficio o de la instrucción del sumario correspondiente, cuando se tratare del o los períodos fiscales próximos a prescribir y dichos actos se notifiquen dentro de los ciento ochenta (180) días corridos inmediatos anteriores a la fecha en que se produzca la correspondiente prescripción.

En todos los casos previstos precedentemente, el efecto de la suspensión opera sobre la prescripción de las acciones y poderes de la Autoridad de Aplicación respecto de los deudores solidarios, si los hubiere".

${ }^{31}$ Los artículos 3966, 3972 y 3973 del Código de 1871 suspendían el curso de la prescripción en caso de personas incapaces que carecieran de representación; contra los herederos que hubieran aceptado la herencia con beneficio de inventario por sus créditos contra la sucesión; contra los menores y personas que estuvieren bajo curatela respecto de las acciones contra los tutores y curadores y viceversa.

${ }^{32}$ CCyC, art. 2541: "Suspensión por interpelación fehaciente. El curso de la prescripción se suspende, por una sola vez, por la interpelación fehaciente hecha por el titular del derecho contra el deudor o el poseedor. Esta suspensión sólo tiene efecto durante seis meses o el plazo menor que corresponda a la prescripción de la acción”. Art. 2542: “Suspensión por pedido de mediación. El curso de la prescripción se suspende desde la expedición por medio fehaciente de la comunicación de la fecha de la audiencia de mediación o desde su celebración, lo que ocurra primero. El plazo de prescripción se reanuda a partir de los veinte días contados desde el momento en que el acta de cierre del procedimiento de mediación se encuentre a disposición de las partes". Art. 2543: "Casos especiales. El curso de la prescripción se suspende: a) entre cónyuges, durante el matrimonio; b) entre convivientes, durante la unión convivencial; c) entre las personas incapaces y con capacidad restringida y sus padres, tutores, curadores o apoyos, durante la responsabilidad parental, la tutela, la curatela o la medida de apoyo; d) entre las personas jurídicas y sus administradores o integrantes de sus órganos de fiscalización, mientras continúan en el ejercicio del cargo; e) a favor y en contra del heredero con responsabilidad limitada, respecto de los reclamos que tienen por causa la defensa de derechos sobre bienes del acervo hereditario". 


\section{VI - Reclamo administrativo e interrupción del curso de la prescripción}

En el sistema del Código unificado el reclamo administrativo no correlaciona con la categoría de "petición judicial" (art. 2546) como actividad interruptiva de la prescripción en curso. Antes bien cabe incluir al reclamo como una forma de "interpelación fehaciente" (art. 2541) y asignarle efecto suspensivo del curso de la prescripción.

Resulta de interés recordar que el Proyecto elevado por la Comisión creada por el Decreto 191/2011, en su artículo 2548 establecía: "Interrupción por reclamo administrativo. El curso de la prescripción se interrumpe por reclamo administrativo si es exigido por la ley como requisito previo para deducir la acción judicial. El efecto interruptivo se tiene por no sucedido si no se interpone demanda judicial dentro de los plazos previstos en las leyes locales o, en su defecto, por seis (6) meses contados desde que se tiene expedita la vía judicial".

Esta disposición fue eliminada durante el tratamiento legislativo del Proyecto y, naturalmente, no se encuentra en el CCyCfinalmente aprobado por Ley26.994. De todas maneras existe una reiterada y pacífica jurisprudencia que reconoce efecto interruptivo al reclamo administrativo previoala demanda judicial cuando vieneimpuesto por el ordenamiento ${ }^{33}$.

\section{VII - Colofón}

Quienes pensamos que es necesario reducir paulatinamente el "unitarismo solapado" que denunciara Pedro J. Frías y que sigue siendo necesario abogar por un federalismo real, adherimos a la reforma.

Es cierto que, frente al déficit presupuestario crónico que padecen las provincias, se corre el riego de que establezcan plazos de prescripción desorbitados. Entonces deberá aparecer en escena el control judicial de razonabilidad tomando como referencia el plazo genérico de cinco años y el plazo especial de dos años para los créditos que se devengan por años o plazos periódicos más cortos (arts. 2560 y 2562 inc. "c" del CCyC). Sería saludable que las provincias no excedieran el plazo de cinco años el cual, por otra parte, ya constituía una costumbre jurídica antes de la reforma en aquellas provincias que así lo establecieron expresamente y también como consecuencia de la consolidación de la tesis centralista que hizo aplicable en los Estados locales el art. 4027 inc. $3^{\circ}$ del Código Civil.

\footnotetext{
${ }^{33}$ Así por ejemplo la Suprema Corte de Justicia de la Provincia de Buenos Aires tiene decidido que "el principio emergente de la doctrina judicial que asimila el reclamo administrativo a la demanda prevista en el art. 3986 del Código Civil como acto idóneo para la interrupción de la prescripción, debe aplicarse en la medida en que exista identidad entre el derecho reclamado y la pretensión que luego se demande" (causa B-53.074, Iglesias, Julio César c/ Prov. de Buenos Aires, 4.4.1995, A y S 1995-I-678). Y en algunos casos relacionados con el ejercicio del poder de policía del trabajo, el Alto Tribunal entendió que "no cabe distinguir entre el reclamo administrativo que viene impuesto como exigencia previa ala instancia judicial y el que voluntariamente formula el trabajador" (causas L-85.120, Alarcón Cáceres, Francisca c/ Ministerio de Salud s/ accidente de trabajo, 27.3.2008; L-86.972, H., D. E. c/ Prov. de Buenos Aires s/ accidente de trabajo, 2.12.2009; etc.).
} 